Digit ratio (2D:4D) moderates the impact of sexual cues on men's decisions in ultimatum games

Bram Van den Bergh and Siegfried Dewitte

DEPARTMENT OF MARKETING AND ORGANISATION STUDIES (MO) 


\title{
Digit RATIO (2D:4D) MOderates THE IMPACT OF SEXual CUES ON MEN'S DECISIONS IN ULTIMATUM GAMES.
}

\author{
Bram Van den Bergh \& Siegfried Dewitte \\ Forthcoming in Proceedings of the Royal Society B: Biological Sciences
}

Submission Date: February 2006

\begin{abstract}
Correspondence concerning this article should be addressed to: B. Van den Bergh, KULeuven, Faculty of Economics and Applied Economics, Naamsestraat 69, B-3000 Leuven, Belgium, E-mail: bram.vandenbergh@econ.kuleuven.be
\end{abstract}

\begin{abstract}
Three experimental studies demonstrate that 'sex-related cues' impact human decision making in ultimatum games. In the ultimatum game, two individuals divide a sum of money. The proposer offers a portion of the money to the other player, the responder. If the responder accepts the offer, the money is distributed in agreement with the proposer's offer. If the responder rejects the offer, neither player receives anything. Our studies show that exposure to pictures of sexy women or lingerie increases the likelihood of accepting unfair offers. Digit ratios of responders are reliably associated with responder's behaviour: Males with lower digit ratios are more likely to reject an unfair split in neutral contexts, but more likely to accept unfair offers in sex related contexts.
\end{abstract}




\section{INTRODUCTION}

Many objectives are achieved more effectively if everyone cooperates (e.g. group hunting). However, collaboration requires complicated decisions on how resources (e.g. prey) should be divided among collaborators. The current research focuses on decisions about accepting or rejecting a division of resources. Fairness considerations reduce the likelihood of accepting unfair offers (Brosnan \& de Waal 2003), whereas visceral factors, such as hunger or thirst may increase the acceptance likelihood of unfair distributions of resources (Loewenstein 1996). Evidence points out that testosterone may be related to increased fairness considerations (high testosterone males are more likely to reject unfair distributions, Burnham 2003) while an increase in testosterone levels after exposure to potential mates (Roney et al. 2003) may be associated with a higher likelihood of accepting small offers (Wilson \& Daly 2004). We propose that sex cues moderate the relationship between testosterone and decisions about accepting or rejecting a distribution of resources.

The most widely used instrument in research on bargaining is the ultimatum game, developed by Güth et al. (1982). In the ultimatum game, two players are given the opportunity to split a sum of money. One player, the proposer, offers a fraction of the money to the other player, the responder. If the responder accepts the offer, the money is distributed in agreement with the proposer's offer. If the responder rejects the offer, neither player gets anything (Page et al. 2000). Proposers should realize that responders are willing to accept any positive take-it-or-leave-it offer, since any amount of money is better than no money. Thus, standard economic theory predicts that proposers should offer very small amounts and responders should be willing to accept them (Rubinstein 1982). Nevertheless, systematic deviations from game theoretic equilibria are frequently observed. Proposers make generous offers and responders often reject small, albeit positive, offers (e.g. Henrich et al. 2004; Nowak et al. 2000; Thaler 1988). We hypothesize that exposure to sex cues will impact ultimatum game behavior.

Sex cues lead to changes in what is perceived "just" (Ariely \& Loewenstein 2005; Loewenstein et al. 1997). Fairness norms prescribe a fifty-fifty split in ultimatum games (Henrich et al. 2004; Nowak et al. 2000). We hypothesize that the preference for this normative fair split is reduced 
after exposure to sex related stimuli. Also, exposure to highly attractive women increases male subjects' preference for smaller, earlier rewards (Wilson \& Daly 2004). We propose that the presence (versus the absence) of sex cues increases the likelihood of accepting small and unfair offers made by proposers, because sex cues reduce fairness considerations and lead to a greater preference for small, immediate rewards.

We conjecture that this general effect will be more pronounced among men with lower digit ratios. Evidence suggests that ratio between the length of the index finger (2D) and the ring finger (4D) reflects the degree to which humans are exposed to prenatal androgen. 2D:4D reliably differs by sex: Males tend to have lower values of 2D:4D than females (Manning 2002). Exposure to high prenatal androgens, low prenatal estrogens, or both, may lead to lower digit ratios (Cattrall et al. 2005; Lutchmaya et al. 2004; Manning 2002; Manning et al. 1998; van Anders et al. 2006). 2D:4D partly clarifies individual differences in aspects of mate quality in men. Lower digit ratios are associated with greater sperm numbers (Manning et al. 1998), good health (Manning 2002), higher physical attractiveness (Roney \& Maestripieri 2004; but see Neave et al. 2003), greater number of sexual partners (Hönekopp et al. 2006) and greater number of children fathered (Manning et al. 2000). Superior athletic and musical ability are associated with lower digit ratios (Hönekopp et al. in press; Manning \& Taylor 2001; Sluming \& Manning 2000) and these qualities may be regarded as honest signals of male fitness. The finding that males with low 2D:4D display higher levels of courtship behaviour when in the presence of potential mates (Roney \& Maestripieri 2004) is particularly relevant for the current study. It is known that nontactile visual exposure to females is associated with transient and short-onset increases in male testosterone levels (e.g. Harding 1981; Hellhammer et al. 1985; Purvis \& Haynes 1974; Roney et al. 2003). Since lower digit ratios are associated with greater sensitivity to testosterone (Manning et al. 2003) and higher circulating testosterone levels (Manning et al. 1998) visual exposure to females may particularly affect male subjects with low digit ratios. Because 2D:4D is related to all kinds of different proxies of mate quality (e.g. Manning et al. 2000; Roney \& Maestripieri 2004; Wood et al. 2003), 'mating' contexts might provide powerful cues particularly for males with lower digit ratios. We predict that responder behaviour in ultimatum games after exposure to sex cues will be associated with 2D:4D. 


\section{MATERIALS, METHODS AND RESULTS}

(a) STUDY 1

Participants.

Heterosexual male students $(n=44)$ were recruited via the internet. Their ages ranged from 18 to $28(m=21.5 ; s . d .=2.05)$. Participants were seated in partially enclosed cubicles, which prevented them from communicating with each other. Our sample comprised 41 students participating in return for a fee and 3 students participating for course credit.

Procedure.

In the picture rating task, 15 photographs were randomly displayed on a computer screen and each participant had to rate the attractiveness of these pictures. Two sets of 15 pictures comprised the stimulus materials. In the landscape condition, 15 pictures of landscapes (beaches, fields, mountain ranges, riversides, etc...) were displayed and in the sexy women condition, 15 pictures of non-nude female models were shown to the participants. All pictures were artificially created to enhance experimental control and contained a female model wearing a bra or swimsuit/bikini. The full torso was seen in all photographs.

Subsequently, participants engaged in a seemingly unrelated task and were informed about the rules of the ultimatum game: The proposer had to suggest a split of $€ 10$ and the responder had to accept or reject the proposer's offer. Each participant made two relevant and consequential choices. They recorded both a maximum offer as proposer and a minimum offer they were willing to accept as responder. To avoid anchoring effects, subjects recorded their choices on a visual analog scale with endpoints $€ 0$ and $€ 10$. If the maximum offer equalled or exceeded the responder's minimum demand, the responders would accept the offer and both the proposer and responder would be paid according to their choices. If the proposer's offer was less than the responder's demand, the responder rejected the offer and no deal was made, leaving both the proposer and the responder empty handed. Participants were informed that $20 \%$ of participants would be randomly chosen, that they would be designated either the role of proposer or responder, that they would be partnered with another individual participating to the same experiment and that they would be paid according to their choices. After the game, participants entered their email-address that was used to inform the participants several weeks later about their eventual gains. 
After the ultimatum game, the right-hand was scanned by a male experimenter to evaluate digit ratios (we used the right hand because relations with right hand digit ratio are typically stronger, Manning 2002). Participants positioned their hand palms on the glass plate of a scanner. Lengths of the second and fourth digits were gauged from the ventral proximal crease of the digit to the finger tip by means of an Adobe Photoshop ${ }^{\circledR}$ tool ("measure tool"). We measured from the most proximal crease when there was a band of creases at the base of the digit. The lengths of index (2D) and ring (4D) fingers were measured twice by the same rater with a time lapse of several weeks. Digit ratio measures had a high level of repeatability $($ ICC $=.99)$. In the analysis, we used the average between the two measurements.

Results and discussion.

We assessed the minimum acceptance level of male responders in the ultimatum game. As predicted, participants who had been visually exposed to pictures of sexy women recorded significantly lower minimum acceptance levels $(m=3.19$, s.e. $=0.29)$ than participants who had been visually exposed to pictures of landscapes $(m=3.41$, s.e. $=0.31), F_{1,40}=4.75, p<.05$. This suggests that exposure to sexy women leads to a lower preference for the normative fair split in an ultimatum game. We did not find a main effect of $2 \mathrm{D}: 4 \mathrm{D}, F_{1,40}=1.40, p>.05$. The interaction between condition and 2D:4D was significant, $F_{1,40}=4.70, p<.05$. That is, the negative correlation between 2D:4D and the minimum acceptance level as responder was not significant in the landscape condition (Spearman correlation coefficient, $r_{\mathrm{S}}=-.14, p>.05$ and $n=23$ ) but there was a significant positive correlation between 2D:4D and the minimum acceptance level in the sexy women condition $\left(r_{\mathrm{S}}=.56, p<.01\right.$ and $\left.n=21\right)$. This suggests that male subjects with lower digit ratios have a lower preference for the normative fair split (=record lower minimum acceptance levels) when they have been visually exposed to sexy women (Figure 1).

\section{(b) STUDY 2}

Participants.

Heterosexual male students $(n=37)$ were recruited via the internet and their ages ranged from 18 to $27(m=21 ; s . d .=1.86)$. Our sample comprised 25 students participating in return for a participation fee and 12 students participating for course credit. The same laboratory setting as in study 1 was used.

Procedure. 
In the rating task, one piece of clothing had to be rated on different dimensions. In the T-shirt condition, one T-shirt was evaluated on several aspects (such as quality, colour, appreciation,...) and in the bra condition, one bra was rated on the same dimensions. Subsequently, participants were given instructions about the seemingly unrelated ultimatum game: The proposer had to suggest a split of $€ 10$ and the responder had to accept or reject the proposer's offer. Study 1's procedure was used. After the ultimatum game, the right-hand was scanned by the same male experimenter as in study 1 . The lengths of index (2D) and ring (4D) fingers were measured twice by the same rater with a time lapse of several weeks. Digit ratio measures had a high level of repeatability $(\mathrm{ICC}=.98)$. In the analysis, we used the average between the two measurements.

Results and discussion.

The minimum acceptance level of male responders was assessed. After visual and tactile exposure to a bra, participants recorded significantly lower minimum acceptance levels $(m=$ 3.42 , s.e. $=.39)$ than participants who had been exposed to a T-shirt $(m=3.80$, s.e. $=.38), F_{1,33}=$ $8.88, p<.01$. This suggests that exposure to lingerie leads to a lower preference for the normative fair split in an ultimatum game. We did not find a main effect of $2 \mathrm{D}: 4 \mathrm{D}, F_{1,33}=.49, p>.05$. In line with study 1 , the interaction between condition and 2D:4D was significant, $F_{1,33}=8.76, p<$ .01 . The negative correlation between 2D:4D and the minimum acceptance level as responder was not significant in the T-shirt condition $\left(r_{\mathrm{S}}=-.25, p>.05\right.$ and $\left.n=19\right)$ but there was a significant positive correlation between 2D:4D and the minimum acceptance level in the bra condition $\left(r_{\mathrm{S}}=.48, p<.05\right.$ and $\left.n=18\right)$. This suggests that male subjects with lower digit ratios have a lower preference for the normative fair split (=record lower minimum acceptance levels) when they have been exposed to lingerie (Figure 1).

\section{(c) STUDY 3}

Participants.

Heterosexual male students $(n=95)$ were recruited via the internet and their ages ranged from 19 to $30(m=22 ; s . d .=1.67)$. All students participated in return for a participation fee. The same laboratory setting as in study 1 and study 2 was used.

Procedure.

As in study 1, 15 photographs were randomly displayed on a computer screen. Three sets of 15 pictures comprised the stimulus materials. In the elderly women condition, the photographs 
contained models who appeared to be in their $70 \mathrm{~s}$. In the young women condition, the photographs contained models who appeared to be in their 20s. All models in the elderly and young women condition were displayed with relatively modest, unrevealing clothing. In the sexy women condition, 15 pictures of non-nude female models (the same stimuli as used in study 1) were shown to the participants. Subsequently, participants were given instructions about the supposedly unrelated ultimatum game. Two participants were omitted from analyses, because they did not comply with the instructions. After the ultimatum game, the right-hand was scanned by the same male experimenter as in study 1 and 2. The lengths of index (2D) and ring (4D) fingers were measured twice by the same rater with a time lapse of several weeks. Digit ratio measures had a high level of repeatability (ICC $=.99$ ). In the analysis, we used the average between the two measurements.

Results and discussion.

Consistent with study 1 and study 2, participants who had been visually exposed to sexy women recorded significantly lower minimum acceptance levels $(m=2.75$, s.e. $=.32)$ than participants who had been visually exposed to pictures of elderly women $(m=3.2$, s.e. $=.33)$, or young women $(m=3.54$, s.e. $=.27), F_{2,87}=5.49, p<.01$. Planned contrasts revealed that the minimum acceptance level in the sexy women condition was significantly lower than the responder's demand in the young women condition, $F_{1,87}=9.99, p<.005$, and significantly lower than the demand in the elderly women condition, $F_{1,87}=7.39, p<.01$. This suggests that exposure to sexy women leads to a lower preference for the normative fair split in an ultimatum game. We did not find a significant main effect of $2 \mathrm{D}: 4 \mathrm{D}, F_{1,87}=.23, p>.05$, but in line with study 1 and study 2 , the interaction between condition and 2D:4D was significant, $F_{2,87}=5.42, p<.01$. The negative correlation between 2D:4D and the minimum acceptance level as responder was not significant in the elderly women condition $\left(r_{\mathrm{S}}=-.30, p>.05\right.$ and $\left.n=28\right)$ but there was a significant positive correlation between 2D:4D and the minimum acceptance level in the sexy women condition $\left(r_{\mathrm{S}}=\right.$ $.40, p<.05$ and $n=30$ ). A significant negative correlation between $2 \mathrm{D}: 4 \mathrm{D}$ and the minimum acceptance level was revealed in the young women condition $\left(r_{\mathrm{S}}=-.36, p<.05\right.$ and $\left.n=35\right)$. This suggests that male subjects with lower digit ratios have a lower preference for the normative fair split when they have been visually exposed to sexy women but but will be more likely to reject unfair offers when exposed to young women (Figure 2). 


\section{(d) META-ANALYSIS}

In a 'meta-analysis' of our three experiments, two conditions were constructed. The control condition comprised the landscape (study 1), the T-shirt (study 2), the elderly women and the young women condition (study 3 ). The sex-cue condition comprised the sexy women (study 1 and study 3 ) and the bra condition (study 2). Participants who had been exposed to a sex cue recorded significantly lower minimum acceptance levels $(m=3.07$, s.e. $=.19)$ than participants in the control condition $(m=3.46$, s.e. $=.15), F_{1,170}=23.67, p<.0001$. We did not find a significant main effect of $2 \mathrm{D}: 4 \mathrm{D}, F_{1,170}=1.83, p>.05$, but the interaction between condition and 2D:4D was significant, $F_{1,170}=23.34, p<.0001$. The negative correlation between 2D:4D and the minimum acceptance level was significant in the control condition $(r=-.28, p<.005$ and $n=105)$ and there was a significant positive correlation between 2D:4D and the minimum acceptance level in the sex-cue condition $(r=.42, p<.0005$ and $n=69)$.

\section{GENERAL DISCUSSION}

The ultimatum game may be considered as a lab model of cooperative hunting or reflect dilemmas of food sharing (Page et al. 2000). Lower minimum acceptance levels in ultimatum games are thus not trivial. Three experimental studies demonstrate that a subtle cue related to sex is able to impact decision making. Consistent with the predictions we derived from Wilson \& Daly (2004) and Ariely and Loewenstein (2005) we found that heterosexual males are more likely to accept unfair offers in an ultimatum game after exposure to sex cues. In three experiments, 2D:4D was reliably and consistently related to demand in ultimatum game behaviour. To our knowledge, this is the first demonstration of a Person*Context interaction (e.g. Mischel \& Shoda 1995) for 2D:4D. The significance of this interaction between digit ratio and context is best exemplified by the 'meta-analysis' of our 3 experiments. In control conditions males with lower digit ratios state higher minimum acceptance levels, which is consistent with the finding that males with lower digit ratios have a preference for the normative fair split (Millet \& Dewitte 2006) and with the finding that males with higher testosterone levels are more likely to reject an unfair split in the ultimatum game (Burnham 2003). However, in sex-cue conditions men with lower digit ratios state lower minimum acceptance levels. This is in line with the finding that exposure to highly attractive women causes men to choose a smaller, sooner reward 
over a larger later reward (Wilson \& Daly 2004) and with the finding that sex cues lead to changes in the perception of what is normatively "just" (Ariely \& Loewenstein 2005; Loewenstein et al. 1997). We strongly advocate future research on 2D:4D*Context interactions. The present study stresses the importance of contextual variables that might impact associations between 2D:4D and aspects of phenotype/personality. Context effects may elucidate puzzling inconsistencies. Our results may partly clarify why some reported relationships with 2D:4D are hard to replicate (e.g. the association between testosterone concentrations and digit ratios; Manning et al. 1998, but see Neave et al. 2003): This study suggests that even the physical appearance of the researcher who interacts with respondents, measures digit lengths, etc. might affect the relation between 2D:4D and other variables.

\section{ACKNOWLEDGEMENTS}

The first author is supported by a Junior Researcher (Aspirant) Grant from the Fund for Scientific Research - Flanders, Belgium (FWO). The second author is supported by grant G.0391.03 from the Fund for Scientific Research - Flanders, Belgium (FWO) and a research grant of the Katholieke Universiteit Leuven (OT 03/07). Financial support by Censydiam-Synovate is gratefully acknowledged.

\section{REFERENCES}

Ariely, D. \& Loewenstein, G. (Forthcoming). The heat of the moment: The effect of sexual arousal on sexual decision making. J. Behav. Dec. Making (DOI: 10.1002/bdm.501)

Brosnan, S. F. \& de Waal, F.B.M. 2003 Monkeys reject unequal pay. Nature 425, 297-299. (DOI: 10.1038/nature01963)

Burnham, T. 2003 Caveman economics. Proximate and ultimate causes of non-materially maximizing behavior. Working paper, Boston, MA, Harvard University.

Cattrall, F. R., Vollenhoven, B. J. \& Weston, G. C. 2005 Anatomical evidence for in utero androgen exposure in women with polycystic ovary syndrome. Fertil. Steril. 84(6), 16891692. (DOI: 10.1016/j.fertnstert.2005.05.061) 
Güth, W., Schmittberger, R. \& Schwarze, B. 1982 An experimental analysis of ultimatum bargaining. J. Econ. Behav. Organ. 3, 376-388.

Harding, C. F. 1981 Social modulation of circulating hormone levels in the male. American Zoologist 21, 223-231.

Hellhammer, D., Hubert, W., \& Schurmeyer, T. 1985 Changes in saliva testosterone after psychological stimulation in men. Psychoneuroendocrinology 10, 77-81.

Henrich, J., Boyd, R., Bowles, S., Camerer, C., Fehr, E. \& Gintis, H. 2004 Foundations of Human Sociality: Economic Experiments and Ethnographic Evidence from Fifteen SmallScale Societies. Oxford University Press.

Hönekopp, J., Voracek, M. \& Manning, J. T. 2006 2nd to 4th digit ratio (2D:4D) and number of sex partners: Evidence for effects of prenatal testosterone in men Psychoneuroendocrinology 31(1), 30-37. (DOI: 10.1016/j.psyneuen.2005.05.009)

Hönekopp, J., Manning J. T. \& Müller C. In Press. Digit ratio (2D:4D) and physical fitness in males and females: Evidence for effects of prenatal androgens on sexually selected traits Horm. Behav. (DOI: 10.1016/j.yhbeh.2005.11.006)

Loewenstein, G. 1996 Out of control: Visceral influences on behavior. Organ. Behav. Hum. Decis. Process. 65(3), 272-92.

Loewenstein, G., Nagin, D. \& Paternoster, R. 1997 The effect of sexual arousal on expectations of sexual forcefulness. J. Res. Crime Delinq. 34, 443-473.

Lutchmaya, S., Baron-Cohen, S., Raggatt, P., Knickmeyer, R. \& Manning, J. T. 2004 Second to fourth digit ratios, fetal testosterone and estradiol. Early Hum. Dev. 77, 23-28. (DOI 10.1016/j.earlhumdev.2003.12.002)

Manning, J. T. 2002 Digit ratio: a pointer to fertility, behaviour, and health. New Brunswick, NJ: Rutgers University Press.

Manning, J. T., Barley, L., Walton, J., Lewis-Jones, D. I., Trivers, R. L., Singh, D., Thornhill, R., Rhode, P., Bereczkei, T., Henzi, P., Soler, M. \& Szwed, A. 2000 The 2nd:4th digit ratio, sexual dimorphism, population differences, and reproductive success: Evidence for sexually antagonistic genes? Evol. Hum. Behav. 21, 163-183. (DOI:10.1016/S1090-5138(00)000295) 
Manning, J. T., Bundred, P. E., Newton, D. J. \& Flanagan, B. F. 2003 The 2nd to 4th digit ratio and variation in the androgen receptor gene. Evol. Hum. Behav. 24, 399-405. (DOI: $10.1016 / \mathrm{S} 1090-5138(03) 00052-7)$

Manning, J. T., Scutt, D.,Wilson, J. \& Lewis-Jones, D. I. 1998 The ratio of 2nd to 4th digit length: a predictor of sperm numbers and concentrations of testosterone, luteinizing hormone and oestrogen. Hum. Reprod. 13, 3000-3004. (DOI: 10.1093/humrep/13.11.3000)

Manning, J. T. \& Taylor, R. P. 2001 2nd to 4th digit ratio and male ability in sport: implications for sexual selection in humans. Evol. Hum. Behav. 22, 61-69. (DOI:10.1016/S10905138(00)00063-5)

Millet, K. \& Dewitte, S. 2006 Second to fourth digit ratio and cooperative behavior. Biol. Psychol. 71(1), 111-115. (DOI: 10.1016/j.biopsycho.2005.06.001)

Mischel, W. \& Shoda, Y. 1995 A cognitive-affective system theory of personality: Reconceptualizing situations, dispositions, dynamics, and invariance in personality structure. Psychol. Rev. 102, 246-268.

Neave, N., Laing, S., Fink, B. \& Manning, J. T. 2003 Second to fourth digit ratio, testosterone, and perceived male dominance. Proc. R. Soc. B. 270, 2167-2172. (DOI 10.1098/rspb.2003.2502)

Nowak, M. A., Page, K. \& Sigmund, K. 2000 Fairness versus reason in the ultimatum game. Science 289, 1773-1775. (DOI 10.1126/science.289.5485.1773)

Page, K. M., Nowak, M. A. \& Sigmund, K. 2000 The spatial ultimatum game. Proc. R. Soc. B 267, 2177-2182. (DOI 10.1098/rspb.2000.1266)

Purvis, K. \& Haynes, N. B. 1974 Short-term effects of copulation, human chorionic gonadotrophin injection and non-tactile association with a female on testosterone levels in the male rat. J. Endocrinol. 60, 429-439.

Roney, J. R. \& Maestripieri, D. 2004 Relative digit lengths predict men's behavior and attractiveness during social interactions with women. Human Nature 15, 271-282.

Roney, J. R., Mahler, S. V. \& Maestripieri, D. 2003 Behavioral and hormonal responses of men to brief interactions with women. Evol. Hum. Behav. 24, 365-375. (DOI:10.1016/S10905138(03)00053-9)

Rubinstein, A. 1982 Perfect equilibrium in a bargaining model. Econometrica 50, 97-110. 
Sluming, V. A. \& Manning J. T. 2000 Second to fourth digit ratio in elite musicians: Evidence for musical Ability as an honest signal of male fitness. Evol. Hum. Behav. 21,1-9. (DOI: 10.1016/S1090-5138(99)00026-4)

Thaler, R. H. 1988 The ultimatum game. J. Econ. Perspect. 2, 195-206.

van Anders, S. M., Vernon P. A. \& Wilbur C. J. 2006 Finger-length ratios show evidence of prenatal hormone-transfer between opposite-sex twins. Horm. Behav. 49(3), 315-319 (DOI: 10.1016/j.yhbeh.2005.08.003

Wilson, M. \& Daly, M. 2004 Do pretty women inspire men to discount the future? Proc. R. Soc. Lond. B (Suppl.) 271, S177-S179. (DOI: 10.1098/rsbl.2003.0134)

Wood, S., Vang, E., Manning, J. T., Walton, J., Troup, S., Kingsland, C. \& Lewis-Jones I. D. 2003 The ratio of 2 nd to 4 th digit length in azoospermic males undergoing surgical sperm retrieval: Predictive value for sperm retrieval and on subsequent fertilization and pregnancy rates in IVF/ICSI cycles. J. Androl. 24, 871-877.

\section{FIGURE CAPTIONS}

Figure 1. Scatterplot of right-hand 2D:4D ratio and minimum acceptance level in an ultimatum game. (a) Study 1, landscape condition. (b) Study 1, sexy women condition. (c) Study 2, T-shirt condition. (d) Study 2, bra condition.

Figure 2. Scatterplot of right-hand 2D:4D ratio and minimum acceptance level in an ultimatum game in Study 3. (a) Elderly women condition. (b) Young women condition. (c) Sexy women condition. 
(a)

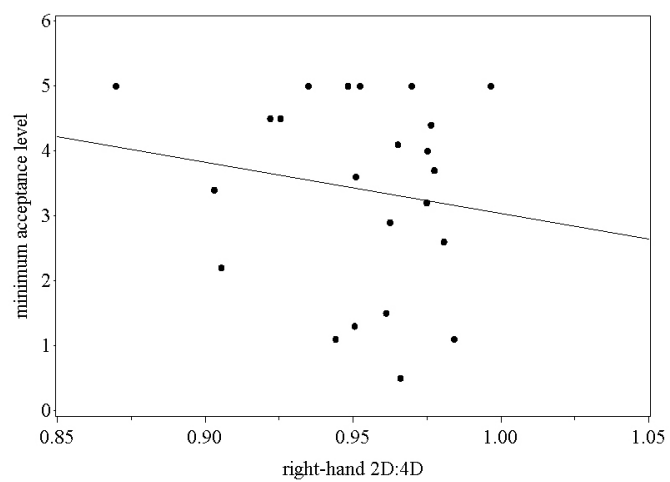

(c)

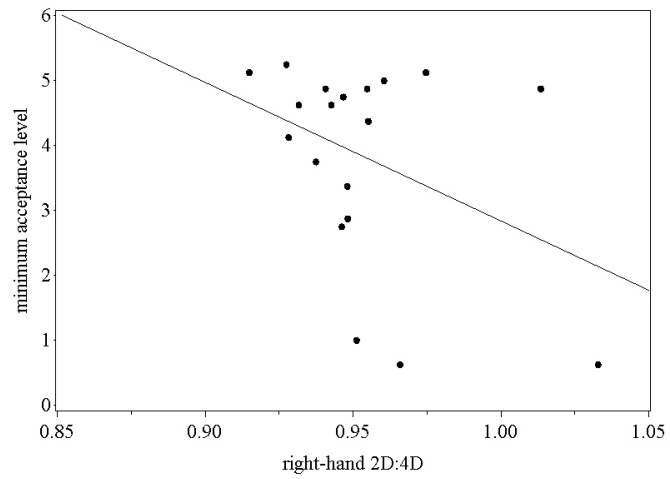

(b)

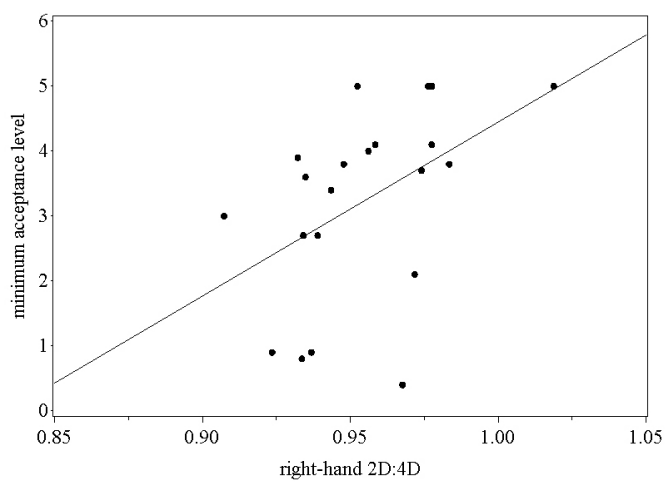

(d)

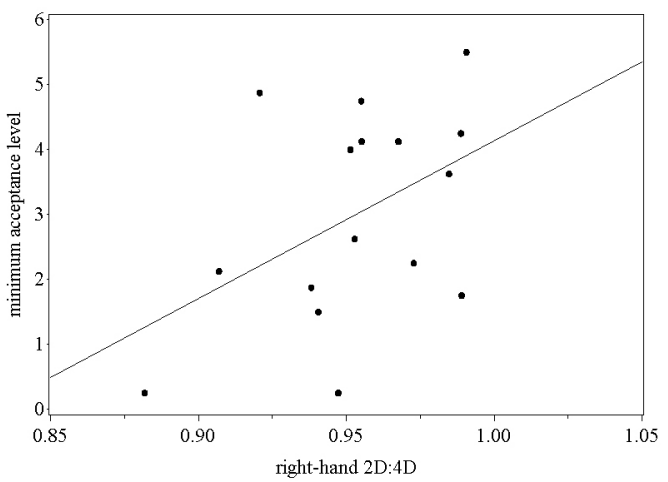


(a)

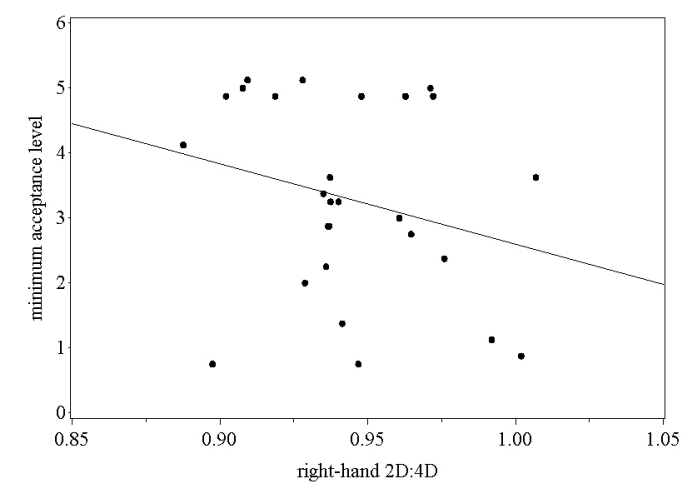

(b)

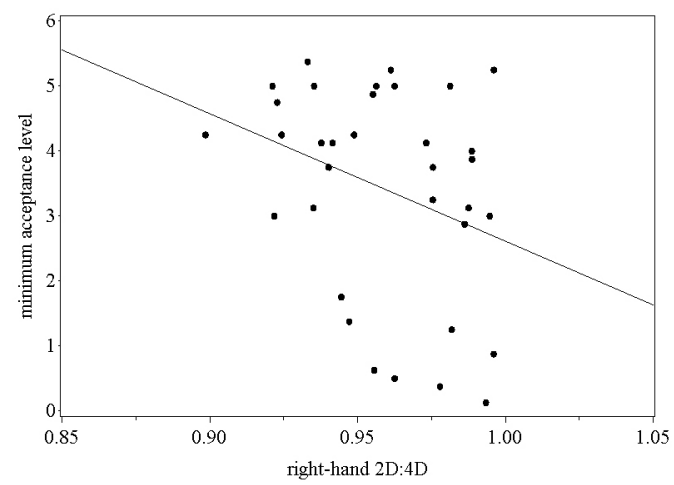

(c)

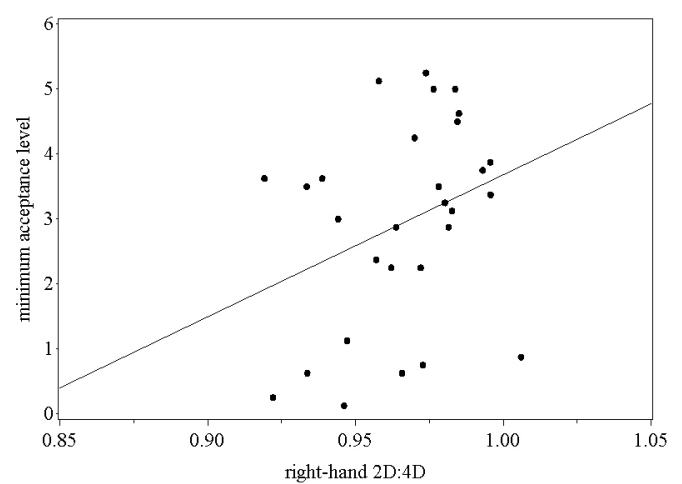

